\title{
Xenopus connexins: how frogs bridge the gap
}

\begin{abstract}
Animal species use specialized cell-to-cell channels, called gap junctions, to allow for a direct exchange of ions and small metabolites between their cells' cytoplasm. In invertebrates, gap junctions are formed by innexins, while vertebrates use connexin $(\mathrm{Cx})$ proteins as gap-junction-building blocks. Recently, innexin homologs have been found in vertebrates and named pannexins. From progress in the different genome projects, it has become evident that every class of vertebrates uses their own unique set of Cxs to build their gap junctions. Here, we review all known Xenopus Cxs with respect to their expression, regulation, and function. We compare Xenopus Cxs with those of zebrafish and mouse, and provide evidence for the existence of several additional, non-identified, amphibian Cxs. Finally, we identify two new Xenopus pannexins by screening EST libraries.
\end{abstract}

Key words Xenopus $\cdot$ connexin $\cdot$ pannexin $\cdot$ gap junction development mouse zebrafish

\section{Introduction}

Many of today's genes find their origins in ancient prototypes. They first appeared in pro- and uni-cellulars, and function in basic cell metabolism or division. The evolutionary leap into integrated multicellular life forms demanded the exchange of information between the co-operating cells, for instance, providing positional information to generate the body plan of the organism.

\footnotetext{
Teun P. de Boer · Marcel A.G. van der Heyden $(\varangle)$

Department of Medical Physiology

University Medical Center Utrecht

Yalelaan 50, 3584 CM Utrecht

The Netherlands

Tel: +31302538418

Fax: +33 302539036

E-mail: m.a.g.vanderheyden@med.uu.nl
}

Many of the patterning genes are thought to have found their origin at that time. Cells also started communication by many different secreted hormones and transmembrane receptor molecules, whereby old genes adapted to new functions and new genes were added to the so-called metazoan "genetic toolkit". Furthermore, direct cell-to-cell communication was established by means of gap junctions in animal species. Gap junctions are found in all vertebrates and invertebrates.

Upon the discovery of the vertebrate gap-junction proteins in the mid-1980s, the so-called connexin (Cx) molecules, it became obvious that sequence-related invertebrate Cxs were absent. More recently, it became clear from Drosophila and Caenorhabditis elegans genome projects that proteins structurally related to Cxs are present in these invertebrates, and are now known as innexins (Phelan and Starich, 2001). It appears that innexins predate $\mathrm{Cxs}$ that have evolved independently (Stout et al., 2004). The finding of $\mathrm{Cx}$ molecules in invertebrate chordates demonstrates that Cxs have evolved earlier than was initially thought (Sasakura et al., 2003; White et al., 2004), but still after the appearance of innexins. As a result of an in-depth search for innexin sequences present in the vertebrate genomes, several orthologs were identified in mouse, rat, and man, and subsequently named pannexins (from the Latin pan, all, and nexus, connection) (reviewed by Panchin, 2005). Functional analyses demonstrated the ability of the pannexins to form functional gap junctions (Bruzzone et al., 2003). Furthermore, it is argued that innexins, pannexins, and Cxs are members of three different gene families, of which the first one is not coexpressed with the latter two in the same organism (White et al., 2004). Most peculiarly, it became clear that even between the different vertebrate classes, many differences in $\mathrm{Cx}$ molecules exist, and for many mammalian Cxs, no genuine ortholog can be easily nominated in birds, fish, amphibians, or tunicates on the basis of sequence characteristics only. It has become clear that every class of vertebrates uses its own unique set of Cxs to build their gap junctions. 
This review focuses on amphibian Cxs, in particular, Xenopus. For excellent recent reviews on Cxs in human disease and mammalian development, we refer to Wei et al. (2004) and Houghton (2005). Here, we review Xenopus Cx expression patterns, regulation, and functional properties and compare these with $\mathrm{Cxs}$ from other species. Finally, as the genome sequencing projects of Xenopus progress rapidly, we will explore the generated databases for new Xenopus Cx and pannexin molecules.

\section{Xenopus Cxs}

While genome sequencing reveals that mouse and human express at least 20 Cxs (Willecke et al., 2002; Söhl and Willecke, 2003), only seven Xenopus Cx isoforms have been described. These are, named by their predicted molecular weight, Cx30, Cx31, Cx38, Cx40.4, Cx41, Cx43, and Cx43.4 (Gimlich et al., 1988, 1990; Ebihara et al., 1989; Yoshizaki and Patiño, 1995; Landesman et al., 2003; De Boer et al., 2005). Based on their nucleotide sequence only, they can be separated into an $\alpha$-group (Cx38, $\mathrm{Cx} 40.4, \mathrm{Cx} 41, \mathrm{Cx} 43)$, a $\beta$-group $(\mathrm{Cx} 30, \mathrm{Cx} 31)$, and an unspecified group (Cx43.4) (De Boer et al., 2005).

Expression data of the Xenopus Cxs, i.e. temporal, developmental pattern, and adult tissue distribution, are summarized in Table 1. Cx31, Cx38, Cx43, and Cx43.4 are maternally expressed and are therefore possibly involved in pre-midblastula transition (MBT) development. Of these, Cx31 and Cx38 have very high expression levels, while pre-MBT expression levels of Cx43 are very low, and detectable by RT-PCR (Landesman et al., 2003), but not by whole-mount in situ hybridization (Van der Heyden et al., 2001a). Cx30 and Cx40.4 are only expressed post-MBT. From the summation in Table 1, it becomes evident that analyses of the embryonic expression patterns and adult tissue distribution are far from complete for many of the Cxs. The best studied are $\mathrm{Cx} 30, \mathrm{Cx} 40.4$, and $\mathrm{Cx} 43$ for which the temporal expression, developmental pattern, and tissue distribution are well established.

\section{Transcriptional and translational control}

Gap-junctional communication is regulated at different levels: transcription, translation, intracellular trafficking, oligomerization, docking, and gating (Segretain and Falk, 2004; Teunissen and Bierhuizen, 2004). Virtually nothing has been described for the latter four mechanisms with respect to Xenopus Cxs.

In recent years, enormous technical progress has been made in producing transgenic Xenopus embryos. This now enables in vivo promoter analysis during development (Amaya et al., 1998; Hirsch et al., 2002). Of the known Xenopus Cxs, only the promoter of $\mathrm{Cx} 43$

Table 1 Expression data

\begin{tabular}{|c|c|c|c|c|}
\hline & Stage & Development & Adult & References \\
\hline $\mathrm{Cx} 30$ & $\begin{array}{l}11,14,15,16,19,20, \\
25,30,35,38,41\end{array}$ & $\begin{array}{l}\text { Hatching gland anus, } \\
\text { endoderm, cement gland, } \\
\text { hindgut, Liver anlage, } \\
\text { kidney }\end{array}$ & $\begin{array}{l}\text { Lung, liver, intestines } \\
\text { stomach, kidney }\end{array}$ & $\begin{array}{l}\text { Gimlich et al. (1988, 1990) } \\
\text { Landesman et al. (2003) } \\
\text { Houtzager (1998) }\end{array}$ \\
\hline $\mathrm{Cx} 31$ & $\begin{array}{l}\text { VI oocyte } \\
\text { Oocyte } \\
2,15,30\end{array}$ & Not determined & Ovary & Landesman et al. (2003) \\
\hline Cx38 & $\begin{array}{l}\text { I-IV oocyte } \\
\text { IV-VI oocyte } \\
\text { Oocyte } \\
1,2,8,9,10\end{array}$ & Not determined & Ovary & $\begin{array}{l}\text { Gimlich et al. (1990) } \\
\text { Yoshizaki and Patiño (1995) } \\
\text { Ebihara et al. (1989) }\end{array}$ \\
\hline $\mathrm{Cx} 40.4$ & $\begin{array}{l}10,18,22,26 \\
30,35,41\end{array}$ & $\begin{array}{l}\text { Presomitic mesoderm } \\
\text { somites }\end{array}$ & $\begin{array}{l}\text { Brain, heart, stomach, } \\
\text { leg muscle, kidney }\end{array}$ & De Boer et al. (2005) \\
\hline $\mathrm{Cx} 41$ & Oocyte & & Ovary, heart & $\begin{array}{l}\text { Yoshizaki and Patiño (1995) } \\
\text { Landesman et al. (2003) } \\
\text { Meijer (2001) }\end{array}$ \\
\hline $\mathrm{Cx} 43$ & $\begin{array}{l}\text { I-IV oocyte } \\
\text { IV-VI oocyte } \\
\text { Oocyte } \\
1,7,38,41\end{array}$ & $\begin{array}{l}\text { Lens, limb bud, } \\
\text { Notochord, } \\
\text { Branchial arches, } \\
\text { Cement gland, } \\
\text { Glial cells }\end{array}$ & $\begin{array}{l}\text { Lung, liver, intestines, } \\
\text { Stomach, spleen, } \\
\text { Body wall muscle, } \\
\text { Heart*, kidney, brain, } \\
\text { Ovary, testis, eye }\end{array}$ & $\begin{array}{l}\text { Gimlich et al. (1990) } \\
\text { Yoshizaki and Patiño (1995) } \\
\text { Van der Heyden et al. (2000a) } \\
\text { Landesman et al. (2003) } \\
\text { Katbamna et al. (2004) }\end{array}$ \\
\hline $\mathrm{Cx} 43.4$ & $\begin{array}{l}\text { VI oocyte } \\
\text { Oocyte } \\
2,6,8.5,10 \\
15,17,24,30 \\
33,35\end{array}$ & $\begin{array}{l}\text { Neural folds, eye vesicle, } \\
\text { Head, spinal cord, tail, } \\
\text { Branchial arch, brain }\end{array}$ & Ovary & Landesman et al. (2003) \\
\hline
\end{tabular}

\footnotetext{
*No connexin43 expression was found in the working myocardium of the heart. Traces of connexin43 expression were found in whole-
} heart homogenates. 
has been cloned (Van der Heyden et al., 2001b). The immediate upstream regions, with respect to the transcription initiation site, display strong homology to mammalian $\mathrm{Cx} 43$ promoters. This region has been characterized as the proximal promoter in rat $\mathrm{Cx} 43$ (Teunissen et al., 2003). Further upstream, the sequence homology is very limited (own unpublished observations). The proximal promoter region displays developmentally regulated promoter activity that correlates with low Cx43 levels in neurula-stage embryos (st 18/19) and an increased promoter activity in early and late tadpole stages (st 28/29, st 37/38) (Van der Heyden et al., 2001b).

Translational control provides an excellent mechanism for fast adaptation to rapidly changing demands, as the mRNA is already present. The mechanism of translational derepression may play a role in different phases of development or at different locations within the rapidly developing embryo. A few studies investigated translational control of Xenopus Cxs mediated by their $5^{\prime}$ and $3^{\prime}$ untranslated regions. In two elaborate studies, it was demonstrated that the translation efficiency of $\mathrm{Cx} 41$ was strongly affected by the presence of three short upstream open reading frames (uORFs) (Meijer et al., 2000a; Meijer and Thomas, 2003). The first, uORF1, generated the largest inhibition, although translation initiation at this uORF was relatively infrequent. However, the use of a rare leucine codon made the translation elongation of uORF1 fairly slow. Furthermore, the termination codon of UORF1 caused another delay. The combinatorial effect most likely results in upstream ribosome stalling, leading to inhibited mRNA scanning and therefore reduced translation initiation at the downstream $\mathrm{Cx} 41$ coding ORF. Only very limited translational control was observed for Cx30 (Meijer et al., 2000b). A similar mechanism has now been suggested for mouse $\mathrm{Cx} 43$, which also contains multiple uORFs (Pfeifer et al., 2004).

Some Cxs have been detected as molecular targets of upstream signaling pathways. In vitro stimulation of ovarian fragments with human chorionic gonadotropic hormone resulted in decreased $\mathrm{Cx}_{41}$ and $\mathrm{Cx} 43$ levels within $4 \mathrm{hr}$, while $\mathrm{Cx} 38$ expression remained unaffected (Yoshizaki and Patiño, 1995). Subtractive hybridization approaches using animal caps of Wnt3a-injected embryos revealed Cx30 as a target gene for Wnt3a-induced signaling (McGrew et al., 1999). In mammals, $\mathrm{Cx} 43$ has been determined as a genuine Wnt target (Van der Heyden et al., 1998; Ai et al., 2000).

\section{Role of Xenopus Cxs in development}

\section{Patterns of gap-junctional communication in Xenopus}

An important role for gap-junctional communication in embryonic development was proposed in the 1960s
(Potter et al., 1966; reviewed in Furshpan and Potter, 1968). In those initial days, the developmentally powerful Xenopus model system also became involved into this rapidly expanding research field. In 1969, halothane-inhibitory electrical coupling between Xenopus blastomeres was demonstrated (Palmer and Slack, 1969). In contrast, metabolic coupling by fluorescein injection in animal pole cells could not be detected (Slack and Palmer, 1969). Subsequently, electrical coupling and its underlying gap junctions were investigated in detail during the 1970s in cleavage stage embryos, isolated blastomeres, oocyte-follicle interaction systems, neural induction, and other systems (Warner, 1973; DiCaprio et al., 1975, 1976; Sanders and DiCaprio, 1976; Turin and Warner, 1977; Browne et al., 1979; Spray et al., 1979). In the 1980s and 1990s, differences in communication capacity within the developing embryo and regulation of this by upstream signaling pathways and cell cycle transition were reported (Rink et al., 1980; Bluemink et al., 1983; Guthrie, 1984; Van den Hoef et al., 1984; Guthrie et al., 1988; Nagajski et al., 1989; Su et al., 1990; Olson et al., 1991; Olson and Moon, 1992; Krufka et al., 1998; Levin and Mercola, 1998). Many of these studies partly rely on fluorescent dye injection and subsequent whole-mount analysis. Although dye injections in Xenopus blastomeres are relatively easy to perform, their interpretations are rather cumbersome and are prone to technical artifacts, as convincingly shown by Landesman et al. (2000). They repeated many of the previous experiments and injected embryos with different fluorescent and nonfluorescent dyes in combination with non-permeable tracers. While whole-mount analysis by conventional fluorescence microscopy of lucifer yellow-injected embryos indicated communication in many examples, subsequent embryo sectioning revealed this to be an optical artifact. The earlier observed differences in communication when comparing the ventral with the dorsal side of the embryo also appeared to be confused by artifacts caused by a combination of several factors such as differential pigment distribution, cell size, yolk distribution, and the so-called lens artifacts. This led to the conclusion that fluorescent dye injection as a tool for studying gap-junctional communication should be used very carefully. However, injection of the non-fluorescent dye neurobiotin revealed extensive gap-junctional communication between the different blastomeres. In these experiments, no differences in the amount of dye coupling was observed within the different regions of the embryo. Nevertheless, conclusions of earlier studies concerning the existence of communication within the developing embryo and selectivity for different dyes were validated. Using more restricted dyes, regional differences in gap-junctional communication within the developing Xenopus embryo might still be revealed in the end. When using the appropriate methodology, Xenopus will be a valuable model to pursue this goal. 
Manipulating gap junctions during Xenopus development

An early study on the involvement of gap-junctional communication in early Xenopus development demonstrated that blocking of communication by halothane led to delayed cleavage rates and inhibited gastrulation in some embryos (Palmer and Slack, 1969). Warner et al. (1984) injected anti-gap-junction antibodies (raised against rat $\mathrm{Cx} 32$ ) into the right anterodorsal cell of an eight-cell embryo, resulting in a disruption of electrical coupling. The resulting tadpoles bore a characteristic set of abnormalities, like absence or size reduction of the right eye and underdevelopment of the brain at this site. Antibody injection just before first cleavage or in both cells of the two-cell embryo resulted in death before gastrulation. A $\mathrm{Cx} 32-\mathrm{Cx} 43$ chimeric $\mathrm{Cx}$ acts as a dominant-negative $\mathrm{Cx}$ on maternally expressed Cx38 (Paul et al., 1995). Injection of this chimera into the right anterodorsal cell of the eight-cell embryo resulted in communication deficiency in this cell's progeny from stage 7 onward (Paul et al., 1995). This resulted in delamination and extrusion of the affected cells from stage 8 onward. Rescue was seen with co-expression of Cx37, which is not subject to dominant-negative inhibition by the Cx32-Cx43 chimera. The authors did not observe developmental defects in ventrally injected embryos. The developmental defects in the tadpole stages were similar to those reported for the antibody injection study. However, in the antibody inhibition study, no extrusion or delamination was reported. Although the effects of gap-junctional inhibition on development are clear from these examples, they cannot be easily attributed to a specific $\mathrm{Cx}$ isoform.

A strong correlation has been found between $\mathrm{Cx} 30$ expression and hatching of embryos from the vitellin membrane (Levin and Mercola, 2000). Hatching depends on the secretion of hatching-associated enzymes, like metaloproteases. Many secretion processes have been shown to depend on functional gap junctions (reviewed by Serre-Beinier et al., 2002). In the developing embryo, Cx30 is strongly expressed in the hatching gland. The application of three different general gapjunction blockers independently to batches of embryos prior to hatching resulted in strongly inhibited hatching efficiency. Furthermore, targeted expression of the dominant-negative $\mathrm{Cx} 32-\mathrm{Cx} 43$ chimera to the hatching gland also resulted in decreased hatching efficiencies. These data might indicate an important function of Cx30 in hatching. However, it cannot be excluded that other, still unknown, $\mathrm{Cx}$ isoforms function in the hatching gland.

The Xenopus developmental system has been instrumental in establishing a role for gap-junctional communication in generating left-right asymmetry. A comprehensive review on left-right asymmetry incorporating the Xenopus results appeared recently (Levin,
2005). Using a variety of pharmacologic gap-junction inhibitors, Levin and Mercola $(1998,1999)$ were able to induce complete and partial heterotaxia in a large percentage of embryos. The strongest sensitivity was found to occur between stages 5 and 12, while enhanced heterotaxia could be demonstrated until stage 21. Furthermore, either inhibition of dorsal gap-junctional communication by injection of the dominant-negative Cx32-Cx43 chimera or increasing ventral gap-junctional communication by bilateral $\mathrm{Cx} 26$ injection caused significant increases in heterotaxia. In a follow-up paper, it was demonstrated that gap-junctional involvement in heterotaxia was upstream of asymmetric Sonic hedgehog and nodal expression (Levin and Mercola, 1999). The first left-right asymmetric distributed gene product in Xenopus appears to be the $\mathrm{H}^{+} / \mathrm{K}^{+}$-ATPase, which is depleted from the left ventral blastomere at the four-cell stage (Levin et al., 2002). In chick embryos, membrane potential at the left side of the node is more depolarized than on the right side. Given the asymmetric $\mathrm{H}^{+} / \mathrm{K}^{+}$-ATPase distribution, a similar difference in membrane potential seems obvious in Xenopus too. It is hypothesized that the gap junctions play a role in the propagation of a calcium wave in the vicinity of the node (Mercola, 2003). Whether or not the wave itself displays an asymmetric orientation is not clear, but voltage-dependent gap-junction gating (Turin and Warner, 1977; Spray et al., 1979) could display leftright differences as a result of asymmetrical $\mathrm{H}^{+} / \mathrm{K}^{+}$ATPase function.

Like in mouse knock-out studies, Cx redundancy in Xenopus has hampered the ability to attribute certain Cxs to specific roles in development, as described already for $\mathrm{Cx} 30$. Another example came from a study on maternal $\mathrm{Cx} 38$, which, at the time of the study, was the only known maternally expressed $\mathrm{Cx}$. Using antisense technology, expression of Cx38 could be severely inhibited without causing developmental abnormalities (Landesman et al., 2003). This suggested the existence of additional maternal Cxs, which were promptly identified in the same study.

In conclusion, some of the above-mentioned examples display a clear role for Cxs in Xenopus development. Because of $\mathrm{Cx}$ redundancy, however, no one-to-one correlation could be made between phenotype and $\mathrm{Cx}$ isoforms. Solving this problem will require further identification of additional Xenopus Cxs in combination with forward genetic techniques like RNAi.

\section{Interspecies comparisons}

Cxs have evolved relatively late in evolution (Stout et al., 2004), and Cx molecules are restricted to chordata only. Even between the different vertebrate classes, sev- 
eral Cxs appear to have limited sequence homology, while others have high levels of amino acid identity (Van der Heyden et al., 2004). Therefore, it is questionable as to whether every $\mathrm{Cx}$ isoform has a genuine ortholog in other vertebrate classes.

In Fig. 1, a comprehensive amino acid-based sequence comparison between Xenopus and mouse Cxs is depicted. As can be seen, some Xenopus Cxs display a high level of identity to murine $\mathrm{Cx}$ isoforms, i.e. $\mathrm{Cx} 30$, Cx31, and, in particular, Cx43. Other Xenopus Cxs, however, display less or even limited sequence homology, i.e. $\mathrm{Cx} 43.3, \mathrm{Cx} 38$, and $\mathrm{Cx} 40.4$, and thereby it is difficult to indicate a mammalian ortholog, if any, for these.

Similar observations have been made in the studies of zebrafish Cxs (i.e., Dermietzel et al., 2000). There too, some of the zebrafish Cxs display a high degree of amino acid identity, while several others show only limited amounts of amino acid identity to mammals, or higher vertebrates. As stated earlier, by others for zebrafish, "this observation raises the question why evolution does conserve some Cxs .... but not others?" (Zoidl et al., 2004). It seems this issue can now be extended into the Xenopus field. A definitive answer to this intriguing question awaits further research. Triggered by these observations, we questioned whether a comparison of Xenopus and zebrafish Cxs would yield higher levels of amino acid identity than those with mouse. As seen in Fig. 2, this is certainly true for some Cxs (i.e., $\mathrm{XlCx} 40.4$ display a $63 \%$ amino acid identity with DrCx39.9). However, other Cx pairs yield even lower identity levels (i.e., $\mathrm{XlCx} 43$ displays $73.6 \%$ identity with DrCx 43 , but $85.6 \%$ with human $\mathrm{Cx}_{4} 43$ ) when compared with mammalian Cxs. Therefore, Xenopus Cxs might be considered as intermediates between mammals and fish. Of the seven known Xenopus Cxs, six of them have orthologs in either mammals, fish, or both. Only Cx38 appears as a Xenopus-specific Cx isoform. In conclusion, the evolutionary conservation among Cxs appears very complex and seems to result from an interplay between evolutionary history, functional convergence, pleiotropy, and maybe other, unknown mechanisms. Further elucidation of the intriguing evolutionary history for all Cxs will require massive input of comprehensive sequence analyses, developmental expression patterns, and functional data.

Xenopus $\mathrm{Cx} 43$ displays a very high level of amino acid identity to mammalian Cx43 (Van der Heyden et al., 2004). Detailed expression pattern analysis also highlights many similarities in expression during development and in adults. For instance, $\mathrm{Cx} 43$ is expressed in the lens epithelium in frogs and mammals, and it has almost identical expression patterns during limb outgrowth in both classes (Van der Heyden et al., 2001a and references therein). It is therefore most remarkable that other important sites of mammalian $\mathrm{Cx} 43$ expression are not reflected in Xenopus. For instance, no ex- pression is found in the developing somites (Van der Heyden et al., 2001a) or in the working myocardium (Becker et al., 1998; Van der Heyden et al., 2001a). In the developing Xenopus somites, Cx40.4 is expressed instead (De Boer et al., 2005), while in the working myocardium, expression of a $\beta$-variant has been suggested (Becker et al., 1998). Until the evolutionary patterns of $\mathrm{Cx}$ distribution have been elucidated in more detail, it remains speculative whether $\mathrm{Cx} 43$ in the lens epithelium, developing limb buds, and notochord are the ancient sites of expression, while myocardial and somitic functions of $\mathrm{Cx} 43$ in mammals have been acquired more recently.

Analysis of the electrophysiological properties of the cloned Xenopus Cxs has been limited to three isoforms. Several studies were performed on Cx38, while functional descriptions of $\mathrm{Cx} 43.3$ and $\mathrm{Cx} 40.4$ were only covered in one study (see Table 2 for references). Although not unexpected and while the analyses are far from complete, it appears that Xenopus Cxs behave in a manner similar to their mammalian counterparts.

\section{Additional Xenopus Cxs?}

When compared with humans, mouse, and zebrafish, relatively few Cxs have been described in Xenopus. At least two observations suggest the existence of additional amphibian Cxs. First, the cumulative expression pattern of all seven known Xenopus Cxs does not cover every structure in the developing frog, leaving "white areas" to be filled in by additional Cxs. Second, from the genome sequencing projects of Xenopus, it has become evident that additional $\mathrm{Cx}$-like sequences are present in the genomic and EST databases. Screening of the mouse and human genome for Cxs resulted in the identification of 20 and $21 \mathrm{Cx}$ isoforms in the fully sequenced mouse and human genomes (Willecke et al., 2002, Söhl and Willecke, 2003). Exploiting the rapid progress in the Xenopus genome sequencing projects, we screened the Xenopus ESTs databases for additional Cxs. This resulted in the identification of full-length sequences for Cx25 (BC055269) and Cx26 (BC043797) and a partial sequence for Cx50 (BQ737050). Cx25 is most similar to human Cx25 (64.4\% amino acid identity), Cx26 displays the strongest identity with mouse Cx26 (65.5\%), while the partial Cx50 sequence has a more than $65 \%$ identity to mouse $\mathrm{Cx} 50$ within the overlapping region. Given that at the time of screening the EST database contained over 400,000 ESTs (compared with over 4,000,000 for mouse), it can be expected that even more Cxs are hidden within the Xenopus genome.

When screening the databases for other amphibian Cxs, we obtained two partial $\mathrm{Cx}$ sequences each in the Axolotl (Ambystoma mexicanum) and the Japanese fire- 

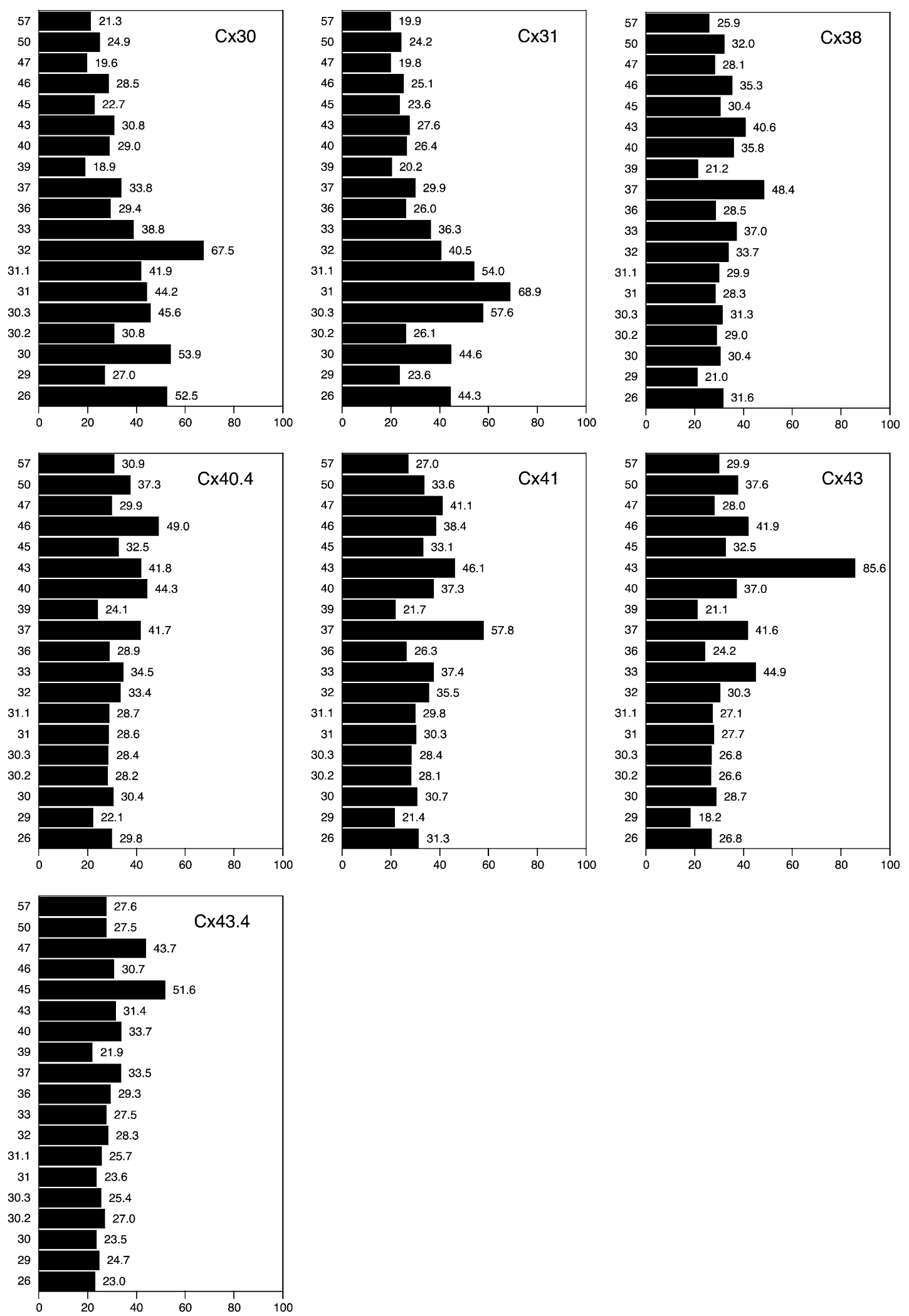

Fig. 1 Comparison of Xenopus and mouse connexins (Cxs). Percentage of amino acid-based identity ( $x$-axis) of a Xenopus $\mathrm{Cx}$ (inCxs (left axis). Identity percentages are displayed at the right of dicated at the top right in each graph) is plotted against 21 mouse each bar. 

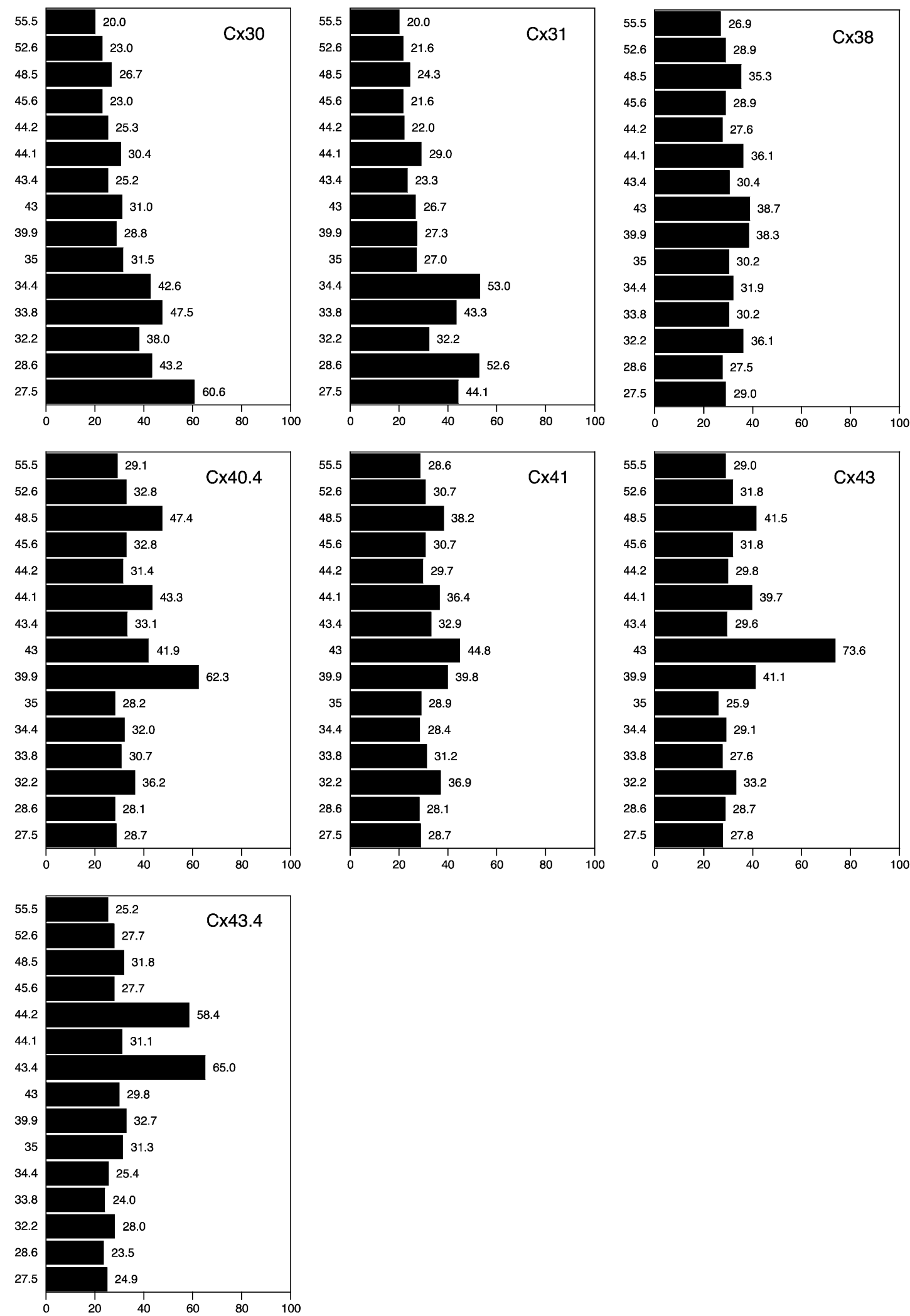

Fig. 2 Comparison of Xenopus and zebrafish connexins (Cxs). Percentage of amino acid-based identity ( $x$-axis) of a Xenopus Cx (indicated at the top right in each graph) is plotted against 15 zebrafish
Cxs (left axis). Identity percentages are displayed at the right of each bar. 
Table 2 Electrophysiological properties

\begin{tabular}{|c|c|c|c|c|c|}
\hline & $\begin{array}{l}\text { Single channel } \\
\text { conductance } \\
\text { (pS) }\end{array}$ & $\begin{array}{l}V_{0} \\
(\mathrm{mV})\end{array}$ & $\begin{array}{l}G_{\min } \\
(\%)\end{array}$ & $\begin{array}{l}\text { Hemi- } \\
\text { channels }\end{array}$ & References \\
\hline Cx38 & - & $\sim 25$ & $\sim 35$ & Yes & $\begin{array}{l}\text { Ebihara et al. } \\
\text { (1989, 1996) } \\
\text { Enkvetchakul } \\
\text { et al. (2003) } \\
\text { Bruzzone } \\
\text { et al. (1994) }\end{array}$ \\
\hline $\mathrm{Cx} 40.4$ & $90-120$ & $\sim 55$ & $\sim 40$ & ND & $\begin{array}{l}\text { De Boer } \\
\text { et al. }(2005)\end{array}$ \\
\hline $\mathrm{Cx} 43.4$ & 35 & $\sim 20$ & 5 & ND & $\begin{array}{l}\text { Landesman } \\
\text { et al. (2003) }\end{array}$ \\
\hline
\end{tabular}

belly newt (Cynops pyrrhogaster) databases. AmCx45 is likely the ortholog of XlCx43.4 (81.4\% identity over 44 amino acids of available sequence), and $\mathrm{AmCx} 31 \mathrm{might}$ be the X1Cx30 ortholog (52.6\% identity over 134 amino acids). $\mathrm{CpCx} 43$ is the ortholog of $\mathrm{XlCx} 43 \quad(82.3 \%$ identity over 304 amino acids), while $\mathrm{CpCx} 35$ has no obvious ortholog in Xenopus $(<30 \%$ identity over 258 amino acids), and is likely another unknown amphibian $\mathrm{Cx}$.

\section{Identification of Xenopus pannexins}

Cxs have long been considered as the only gap-junctionforming proteins in vertebrates, while invertebrate gap junctions are formed by an unrelated protein family named as innexins. Recently, however, three orthologs of innexins were identified in the genomes of several vertebrates like mouse, rat, and man (reviewed by Panchin, 2005). These so-called pannexins (PANX) are able to confer electrical coupling in a classical paired Xenopus oocyte assay (Bruzzone et al., 2003). Human and mouse PANX1 mRNAs are ubiquitously expressed, while PANX2 is brain specific (Baranova et al., 2004).

To look for the presence of pannexins in Xenopus, we screened $X$. tropicalis and $X$. laevis EST databases with a region of mouse PANX1 (NP_062355), PANX2 (NP_001002005), and PANX3 (NP_766042) encompassing the highly conserved first two transmembrane regions and their intervening extracellular stretch of amino acids (Baranova et al., 2004). This resulted in one positive EST for $X$. laevis (BU912264), most similar to mouse PANX1, and two different positive ESTs for X. tropicalis (CX978500 and CX799160), most similar to mouse PANX1 and PANX2, respectively. No ortholog was identified for mouse PANX3. Amino acid identity of XIPANX1 (stretch of 153 amino acids) is $54.9 \%$ with mouse PANX1 and $45.5 \%$ with zebrafish PANX1. The amino acid identity of XtPANX1 (N-terminal 217 amino acids) with mouse and zebrafish PANX1 is $75.6 \%$ and $61.9 \%$, respectively. XtPANX2 identity with mouse PANX2 is $89.9 \%$ over the $\mathrm{N}$ terminal 129 amino acids. Alignment of the Xenopus pannexins with those of mouse and zebrafish is depicted in Fig. 3. Amino acids shaded in green represent conserved sites between invertebrate innexins and vertebrate pannexins (Baranova et al., 2004). These data demonstrate the presence of genuine expressed pannexins within the Xenopus genomes.

XIPANX1 was identified in an oocyte EST library. XtPANX1 was found in EST databases from oocyte, gastrula, neurula, tailbud, intestine, testes, and brain EST libraries. Finally, XtPANX2 was present in an adult brain EST library. These provisional expression data are in accordance with the tissue distribution of mouse and human PANX1 and PANX2.

As for other vertebrates, ensued by our identification of pannexins in Xenopus, we can now regard these proteins as an alternative source of gap-junction proteins in the frog too.

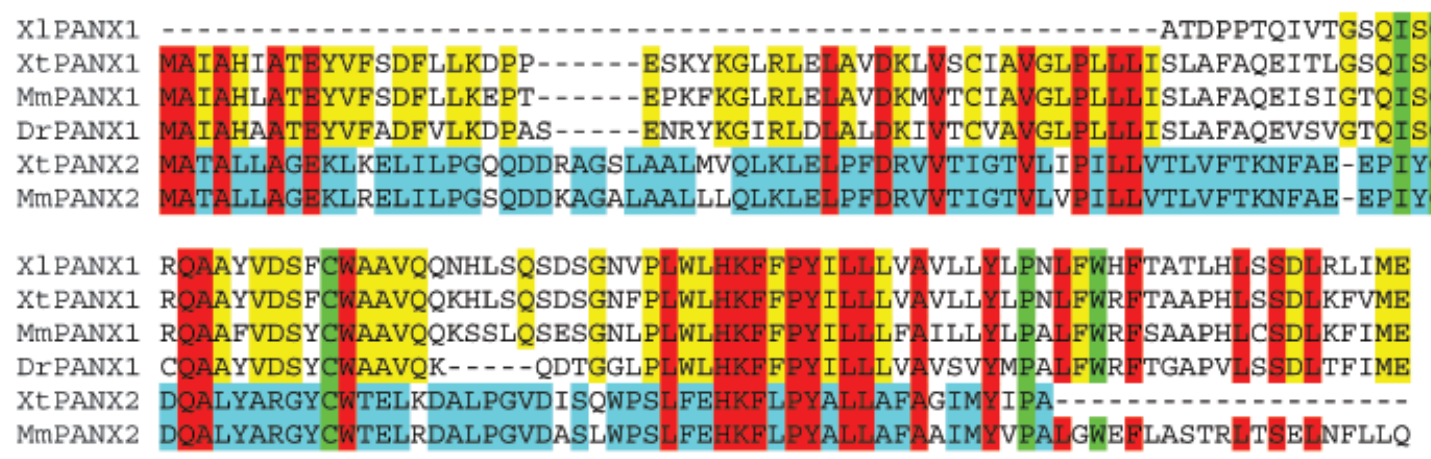

Fig. 3 Amino acid alignment of Xenopus, mouse, and zebrafish pannexins. The sequence encompasses the $\mathrm{N}$-terminus, transmembrane regions 1 and 2, and the first extracellular region. XIPANX, $X$. laevis pannexin; XtPANX, X. tropicalis pannexin; MmPANX, mouse pannexin; DrPANX, zebrafish pannexin. Yellow shaded

conserved between PANX1, blue shaded conserved between PANX2, red shaded conserved between all depicted PANXs, green shaded conserved between invertebrate innexins and vertebrate PANXs (according to Baranova et al., 2004). 


\section{Conclusions and future directions}

Although once a very popular model system in gapjunction research, Xenopus is currently merely used as a producer of oocytes for the study of ectopically expressed xeno-Cxs. The molecular identification of Xenopus Cxs has become less of a priority than mammalian and zebrafish Cxs in recent decades. Nevertheless, $\mathrm{Cx}$ research in Xenopus has clearly elucidated some important aspects of $\mathrm{Cx}$ regulation at the translational level. Furthermore, it has played an important role in understanding the developmental roles of Cxs, for instance, in establishing the left-right axis, valuable knowledge that reaches beyond the amphibians.

Two developments within the Xenopus field will boost molecular approaches in this model system with respect to Cxs. Firstly, the genome project has already elucidated several additional Cxs in this species. The number of identified Xenopus Cxs will increase further in the coming years, and we might well end up in the same numbers as in mammals. Secondly, the transgenic and RNAi approaches in this model system will be very useful in pinpointing the role of specific Cxs in developmental processes. Furthermore, upon completion of the genome projects, a comprehensive comparison of the complete $\mathrm{Cx}$ sets from mouse, chicken, zebrafish, Xenopus, and Ciona will likely shed more light on the enigmatic evolution of Cxs. Finally, the presence of pannexins in Xenopus hints at an alternative source of gap-junction proteins in the frog.

Acknowledgments We thank Jennifer Moore for helpful comments on the manuscript.

\section{References}

Ai, Z., Fischer, A., Spray, D.C., Brown, A.M. and Fishman, G.I. (2000) Wnt-1 regulation of connexin43 in cardiac myocytes. J Clin Invest 105:161-171.

Amaya, E., Offield, M.F. and Grainger, R.M. (1998) Frog genetics: Xenopus tropicalis jumps into the future. Trends Genet 14: 253-255.

Baranova, A., Ivanov, D., Petrash, N., Pestova, A., Skoblov, M., Kelmanson, I., Shagin, D., Nazarenko, S., Geraymovych, E., Litvin, O., Tiunova, A., Born, T.L., Usman, N., Staroverov, D., Lukyanov, S. and Panchin, Y. (2004) The mammalian pannexin family is homologous to the invertebrate innexin gap junction proteins. Genomics 83:706-716.

Becker, D.L., Cook, J.E., Davies, C.S., Evans, W.H. and Gourdie, R.G. (1998) Expression of major gap junction connexin types in the working myocardium of eight chordates. Cell Biol Int 22:527-543.

Bluemink, J.G., Hage, W.J., Van den Hoef, M.H.F. and Dictus, W.J.A.G. (1983) Freeze-fracture electron microscopy of membrane changes in progesterone-induced maturing oocytes and eggs of Xenopus laevis. Eur J Cell Biol 31:85-93.

Browne, C.L., Wiley, H.S. and Dumont, J.N. (1979) Oocyte-follicle cell gap junctions in Xenopus laevis and the effects of gonadotropin on their permeability. Science 203:182-183.

Bruzzone, R., Hormuzdi, S.G., Barbe, M.T., Herb, A. and Monyer, H. (2003) Pannexins, a family of gap junction proteins expressed in brain. Proc Natl Acad Sci U.S.A. 100: 13644-13649.

Bruzzone, R., White, T.W. and Paul, D.L. (1994) Expression of chimeric connexins reveals new properties of the formation and gating behavior of gap junction channels. J Cell Sci 107: 955-967.

De Boer, T.P., Kok, K., Neuteboom, K.I.E., Spieker, N., De Graaf, J., Destrée, O.H.J., Rook, M.B., Van Veen, T.A.B., Jongsma, H.J., Vos, M.A., De Bakker, J.M.T. and Van der Heyden, M.A.G. (2005) Cloning and functional characterization of a novel connexin expressed in somites of Xenopus laevis. Dev Dyn 233: 864-971.

Dermietzel, R., Kremer, M., Paputsoglu, G., Stang, A., Skerrett, I.M., Gomès, D., Srinivas, M., Janssen-Bienhold, U., Weiler, R., Nicholson, B.J., Bruzzone, R. and Spray, D.C. (2000) Molecular and functional diversity of neural connexins in the retina. $\mathbf{J}$ Neurosci 20:8331-8343.

DiCaprio, R.A., French, A.S. and Sanders, E.J. (1975) Intercellular connectivity in the eight-cell Xenopus embryo. Biophys J 15: 373-389.

DiCaprio, R.A., French, A.S. and Sanders, E.J. (1976) On the mechanism of electrical coupling between cells of early Xenopus embryos. J Membrane Biol 27:393-404.

Ebihara, L. (1996) Xenopus connexin 38 forms hemi-gap-junctional channels in the nonjunctional plasma membrane of Xenopus oocytes. Biophys J 71:742-748.

Ebihara, L., Beyer, E.C., Swenson, K.I., Paul, D.L. and Goodenough, D.A. (1989) Cloning and expression of a Xenopus embryonic gap junction protein. Science 243:1194-1195.

Enkvetchakul, D., Ebihara, L. and Nichols, C.G. (2003) Polyamine flux in Xenopus oocytes through hemi-gap junction channels. J Physiol 553:95-100.

Furshpan, E.J. and Potter, D.D. (1968) Low-resistance junctions between cells in embryos and tissue culture. Curr Top Dev Biol 3:95-127.

Gimlich, R.L., Kumar, N.M. and Gilula, N.B. (1988) Sequence and developmental expression of mRNA coding for a gap junction protein in Xenopus. J Cell Biol 107:1065-1073.

Gimlich, R.L., Kumar, N.M. and Gilula, N.B. (1990) Differential regulation of the levels of three gap junction mRNAs in Xenopus embryos. J Cell Biol 110:597-605.

Guthrie, S.C. (1984) Patterns of junctional communication in the early amphibian embryo. Nature 311:149-151.

Guthrie, S.C., Turin, L. and Warner, A. (1988) Patterns of junctional communication during development of the early amphibian embryo. Development 103:769-783.

Hirsch, N., Zimmerman, L.B. and Grainger, R.M. (2002) Xenopus, the next generation: $X$. tropicalis genetics and genomics. Dev Dyn 225:422-433.

Houghton, F.D. (2005) Role of gap junctions during early embryo development. Reproduction 129:129-135.

Houtzager, E. (1998) The role of connexins and the function of dorsal endoderm in embryogenesis of Xenopus laevis. Thesis, Utrecht University, the Netherlands, pp. 39-92.

Katbamna, B., Jelaso, A. and Ide, C.F. (2004) Connexin43 expression in glial cells of developing rhombomeres of Xenopus laevis. Int J Dev Neurosci 22:47-55.

Krufka, A., Johnson, R.G., Wylie, C.C. and Heasman, J. (1998) Evidence that dorsal-ventral differences in gap junctional communication in the early Xenopus embryo are generated by $\beta$-catenin independent of cell adhesion. Dev Biol 200: $92-102$.

Landesman, Y., Goodenough, D.A. and Paul, D.L. (2000) Gap junctional communication in the early Xenopus embryo. J Cell Biol 150:929-936.

Landesman, Y., Postma, F.R., Goodenough, D.A. and Paul, D.L. (2003) Multiple connexins contribute to intercellular communication in the Xenopus embryo. J Cell Sci 116:29-38.

Levin, M. (2005) Left-right asymmetry in embryonic development: a comprehensive review. Mech Dev 122:3-25. 
Levin, M. and Mercola, M. (1998) Gap junctions are involved in the early generation of left-right asymmetry. Dev Biol 203: $90-105$.

Levin, M. and Mercola, M. (1999) Gap junction-mediated transfer of left-right patterning signals in the early chick blastoderm is upstream of Shh asymmetry in the node. Development 126: 4703-4714.

Levin, M. and Mercola, M. (2000) Expression of connexin 30 in Xenopus embryos and its involvement in hatching gland function. Dev Dyn 219:96-101.

Levin, M., Thorlin, T., Robinson, K.R., Nogi, T. and Mercola, M. (2002) Asymmetries in $\mathrm{H}^{+} / \mathrm{K}^{+}$-ATPase and cell membrane potentials comprise a very early step in left-right patterning. Cell 111:77-89.

McGrew, L.L., Takemaru, K.-I., Bates, R. and Moon, R.T. (1999) Direct regulation of the Xenopus engrailed-2 promoter by the Wnt signaling pathway, a molecular screen for Wnt-responsive genes, confirm a role for Wnt signaling during neural patterning in Xenopus. Mech Dev 87:21-32.

Meijer, H.A. (2001) Translational control of connexin 30 and 41 mRNAs in Xenopus laevis embryos. Thesis, Utrecht University, the Netherlands, pp. 87-93.

Meijer, H.A., Dictus, W.J.A.G., Keuning, E.D. and Thomas, A.A.M. (2000a) Translational control of the Xenopus laevis Connexin-41 $5^{\prime}$-untranslated region by three upstream open reading frames. J Biol Chem 275:30787-30793.

Meijer, H.A., Dictus, W.J.A.G. and Thomas, A.A.M. (2000b) Cloning and analysis of the untranslated regions of the Xenopus laevis Connexin30 mRNA. Gene 258:71-76.

Meijer, H.A. and Thomas, A.A.M. (2003) Ribosomes stalling on uORF1 in the Xenopus Cx41 5'UTR inhibits downstream translation initiation. Nucleic Acids Res 31:3174-3184.

Mercola, M. (2003) Left-right asymmetry: nodal points. J Cell Sci 116:3251-3258

Nagajski, D.J., Guthrie, S.C., Ford, C.C. and Warner, A.E. (1989) The correlation between patterns of dye transfer through gap junctions and future developmental fate in Xenopus: the consequences of u.v. irradiation and lithium treatment. Development 105:747-752.

Olson, D.J., Christian, J.L. and Moon, R.T. (1991) Effect of Wnt-1 and related proteins on gap junctional communication in Xenopus embryos. Science 252:1173-1176.

Olson, D.J. and Moon, R.T. (1992) Distinct effects of ectopic expression of Wnt-1, Activin B, bFGF on gap junctional permeability in 32-cell Xenopus embryos. Dev Biol 151:204-212.

Palmer, J.F. and Slack, C. (1969) Effect of "halothane" on electrical coupling in pregasgrulation embryos of Xenopus laevis. Nature 223:1286-1287.

Panchin, Y. (2005) Evolution of gap junction proteins - the pannexin alternative. J Exp Biol 208:1415-1419.

Paul, D.L., Yu, K., Bruzzone, R., Gimlich, R.L. and Goodenough, D.A. (1995) Expression of a dominant negative inhibitor of intercellular communication in the early Xenopus embryo causes delamination and extrusion of cells. Development 121: 371-381.

Pfeifer, I., Anderson, C., Werner, R. and Oltra, E. (2004) Redefining the structure of the mouse connexin 43 gene: selective promoter usage and alternative splicing mechanisms yield transcripts with different translational efficiencies. Nucleic Acids Res 32: 4550-4562.

Phelan, P. and Starich, T.A. (2001) Innexins get into the gap. Bioessays 23:388-396.

Potter, D.D., Furshpan, E.J. and Lennox, E.S. (1966) Connections between cells of the developing squid as revealed by electrophysiological methods. Proc Natl Acad Sci U.S.A. 55: 328-336.

Rink, T.J., Tsien, R.Y. and Warner, A.E. (1980) Free calcium in Xenopus embryos measured with ion-selective microelectrodes. Nature 283:658-660.
Sanders, E.J. and DiCaprio, R.A. (1976) Intercellular junctions in the Xenopus embryo prior to gastrulation. J Exp Zool 197: 415-421.

Sasakura, Y., Shoguchi, E., Takatori, N., Wada, S., Meinertzhagen, I.A., Satou, Y. and Satoh, N. (2003) A genomewide survey of developmentally relevant genes in Ciona intestinales. Dev Genes Evol 213:303-313.

Segretain, D. and Falk, M.M. (2004) Regulation of connexin biosynthesis, assembly, gap junction formation, and removal. Biochim Biophys Acta 1662:3-21.

Serre-Beinier, V., Mas, C., Calabrese, A., Caton, D., Bauquis, J., Caille, D., Charollai, A., Cirulli, V. and Meda, P. (2002) Connexins and secretion. Biol Cell 94:477-492.

Slack, C. and Palmer, J.F. (1969) The permeability of intercellular junctions in the early embryo of Xenopus laevis, studied with a fluorescent tracer. Exp Cell Res 55:416-419.

Söhl, G. and Willecke, K. (2003) An update on connexin genes and their nomenclature in mouse and man. Cell Comm Adhes 10:173-180.

Spray, D.C., Harris, A.L. and Bennett, M.V.L. (1979) Voltage dependence of junctional conductance in early amphibian embryos. Science 204:432-434.

Stout, C., Goodenough, D.A. and Paul, D.L. (2004) Connexins: functions without junctions. Curr Opin Cell Biol 16:507-512.

Su, J.W., Tertoolen, L.G.J., De Laat, S.W., Hage, W.J. and Durston, A.J. (1990) Intercellular communication is cell cycle modulated during early Xenopus laevis development. J Cell Biol 110:115-121.

Teunissen, B.E.J. and Bierhuizen, M.F.A. (2004) Transcriptional control of myocardial connexins. Cardiovasc Res 62: 246-255.

Teunissen, B.E.J., Jansen, A.T., Van Amersfoorth, S.C.M., O'Brien, T.X., Jongsma, H.J. and Bierhuizen, M.F.A. (2003) Analysis of the rat connexin 43 proximal promoter in neonatal cardiomyocytes. Gene 322:123-136.

Turin, L. and Warner, A. (1977) Carbon dioxide reversibly abolishes ionic communication between cells of early amphibian embryo. Nature 270:56-57.

Van den Hoef, M.H., Dictus, W.J., Hage, W.J. and Bluemink, J.G. (1984) The ultrastructural organization of gap junctions between follicle cells and the oocyte in Xenopus laevis. Eur J Cell Biol 33:242-247.

Van der Heyden, M.A.G., Rook, M.B., Hermans, M.M., Rijksen, G., Boonstra, J., Defize, L.H.K. and Destrée, O.H.J. (1998) Identification of connexin43 as a functional target for Wnt signalling. J Cell Sci 111:1741-1749.

Van der Heyden, M.A.G., Roeleveld, L., Peterson, J. and Destrée, O.H.J. (2001a) Connexin43 expression during Xenopus development. Mech Dev 108:217-220.

Van der Heyden, M.A.G., Roeleveld, L., Reneman, S., Peterson, J. and Destrée, O.H.J. (2001b) Regulated expression of the $X$. tropicalis Connexin43 promoter. Cell Commun Adhes 8: 293-298.

Van der Heyden, M.A.G., Van Eijk, M., Wilders, R., De Bakker, J.M.T. and Opthof, T. (2004) Connexin43 orthologues in vertebrates: phylogeny from fish to man. Dev Genes Evol 214: 261-266.

Warner, A.E. (1973) The electrical properties of the ectoderm in the amphibian embryo during induction and early development of the nervous system. J Physiol (London) 235:267-286.

Warner, A.E., Guthrie, S.C. and Gilula, N.B. (1984) Antibodies to gap-junctional protein selectively disrupt junctional communication in the early amphibian embryo. Nature 311:127-131.

Wei, C.J., Xu, X. and Lo, C.W. (2004) Connexins and cell signaling in development and disease. Annu Rev Cell Dev Biol 20: $811-838$

White, T.W., Wang, H., Mui, R., Litteral, J. and Brink, P.R. (2004) Cloning and functional expression of invertebrate connexins from Halocynthia pyriformis. FEBS Lett 577:42-48. 
Willecke, K., Eiberger, J., Degen, J., Eckardt, D., Romualdi, A., Güldenagel, M., Deutsch, U. and Söhl, G. (2002) Structural and functional diversity of connexin genes in the mouse and human genomes. Biol Chem 383:725-737.

Yoshizaki, G. and Patiño, R. (1995) Molecular cloning, tissue distribution, hormonal control in the ovary of Cx41 mRNA, a novel Xenopus connexin gene transcript. Mol Reprod Dev 42:7-18.

Zoidl, G., Bruzzone, R., Weickert, S., Kremer, M., Zoidl, C., Mitropoulous, G., Srinivas, M., Spray, D.C. and Dermietzel, R. (2004) Molecular cloning and functional expression of $\mathrm{zfCx} 52.6$. J Biol Chem 279:2913-2921. 